\title{
ОСОБЕННОСТИ СОЦИАЛЬНОЙ ПЕРЦЕПЦИИ У ДЕТЕЙ СТАРШЕГО ДОШКОЛЬНОГО ВОЗРАСТА ${ }^{19}$
}

Хузеева Г. Р. (Московский педагогический государственный университет, Москва, Россия)

guzeliya.h@yandex.ru

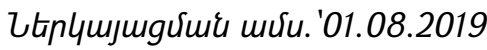

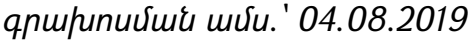

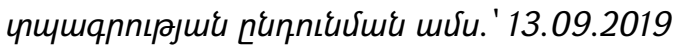

В статье рассматриваются особенности развития эмоционального и когнитивного компонента образа социального взрослого, образа сверстника и особенности восприятия проблемных ситуаций общения в пространстве взаимодействия со сверстниками у детей 5-7 лет. В статье показано, что развитие эмоционального компонента опережает развитие когнитивного компонента социального образа. При этом, содержание и структура образа социального взрослого и образа сверстника имеют как сходства, так и различия. Особенности образа взрослого, сверстника и особенности восприятия и решения проблемных ситуаций отражают основные закономерности коммуникативного развития детей. Обнаружена взаимосвязь между уровнем популярности в группе сверстников и уровнем развития социальной перцепции у детей старшего дошкольного возраста. Показано влияние социального контекста на развитие социальной перцепции у детей 5-7 лет. В статье обозначена проблема разработки технологий сопровождения социального развития детей дошкольного возраста.

Ключевые слова: дети старшего дошкольного возраста, сочиальная перчепчия, образ сочиального взрослого, образ сверстника, проблемные ситуачии общения со сверстниками.

Проблема изучения особенностей социальной перцепции у детей старшего дошкольного возраста является актуальной и перспективной. В рамках современного научного знания проблема социальной перцепции и социального познания, в основном, разрабатывается на стыке когнитивной и социальной психологии. Проблема развития социальной перцепции на разных этапах онтогенеза рассматривается в рамках социальной психологии развития. Методологической основой нашего исследования стали положения Дж. Брунера, Ф. Хайдера, А. Тэшфела, Дж.Тернера, С. Московичи [2]. В отечественной психологии проблема социальной перцепции рассматривается в работах Г.М. Андреевой, А.А. Бодалева, А.И. Донцова, М.И.Лисиной, Е.О.Смирновой [2,4]. Исследования социальной перцепции объединяет общее положение о том, что особенности

19 Исследование выполнено при фринансовой поддержке Проект №17-06-00077-ОГН ОГН-А. Проблема лингвистической идентичности в мультикультурном пространстве 
социальной перцепции определяют предпосылки, процесс и результат взаимодействия, общения человека и успешность его социального функционирования в целом. В изучение закономерностей социальной перцепции используются различные психологические конструкты: «когнитивная схема» в работах Ж. Пиаже, «сбалансированные и несбалансированные структуры» Ф Хайдера, «социальные представления" С. Московичи, “особенности восприятия аутгруппы и ингруппы» у А. Тешфела, «навыки принятия роли» Роберта Сельмана, «образ себя и других людей» в концепции М.И. Лисиной, «личностный и предметный тип отношения» в работах Е.О. Смирновой. Данные понятия раскрывают различные аспекты социального познания и обосновывают определяющую роль восприятия в ходе социального взаимодействия.

Г.М. Андреева считает, что социальное познание является всегда двусторонним процессом. Процесс социального познания усложняется также тем, что социальные объекты и социальные действия изменчивы, в отличие от объектов окружающего мира. Опираясь на данные особенности, Г.М. Андреева пишет: «Процесс социального познания поэтому намного сложнее, и возможности действительного осмысления социального мира в большей степени связаны с активным действием субъекта познания» [2,С.9]. Автор отмечает важность изучения особенностей социального познания, а также изучение механизмов «конструирования социального мира на разных этапах социализации» [2, С.9]. С точки зрения М.И. Лисиной, определяющей целью общения как отдельного, самостоятельного вида деятельности, является познание себя и других людей. То есть, особенности социального познания определяют процесс и результат развития общения на разных этапах онтогенеза [3]. Развивая идеи М.И. Лисиной, Е.О. Смирнова рассматривает проблему социального познания во взаимосвязи с динамикой развития характера межличностных отношений на разных этапах развития. Эмпирические исследования, проведенные под руководством Е.О. Смирновой, показали тесную взаимосвязь характера межличностных отношений и особенностей общения детей дошкольного возраста [4].

Многие исследователи считают, что именно в дошкольном возрасте закладываются основы социальной успешности или неуспешности. Имеется ряд возрастных особенностей, таких как: эгоцентризм (Ж. Пиаже), несформированные навыки принятия роли (Роберт Сельман) и др., определяющих специфику социального развития детей. При этом, многие исследователи доказывают, что старший дошкольный возраст является сензитивным возрастом для развития опосредованных психических функций, механизмов саморегуляции, морального развития (Авдулова Т.П.) [1], что дает ребенку новые возможности освоения социальной реальности.

Целью данного исследования является выделение особенностей социальной перцепции у детей старшего дошкольного возраста, особенностей эмоционального 
и когнитивного компонента образа социально значимого взрослого, сверстника, восприятия проблемных ситуаций общения, а также определение возможных зон развития, способствующих социальному развитию ребенка дошкольного возраста и влияние роли различных аспектов социального контекста.

\section{Методики исследования}

1. Для определения особенностей эмоционального и когнитивного компонента образа социального взрослого (воспитателя) у детей старшего дошкольного возраста использовалась рисуночная методика «Рисунок воспитателя» (модификация и критерии анализа Г.Р.Хузеева)[1].

2. Для изучения когнитивного и аффективного компонента образа сверстника (представлений о сверстнике, степень дифференцированности представлений и эмоциональное отношение к сверстнику) использовалась проективная методика «Я и мой друг» (модификация и критерии анализа Г. Р. Хузеева, К.Г. Чепухина)[1].

3. Для изучения особенностей восприятия проблемных ситуаций общения в пространстве взаимодействия со сверстниками использовалась методика «Проблемные ситуации» (автор: Е.О.Смирнова, модификация и критерии анализа Е.В.Фомченко)[1].

4. Для определения социометрического статуса в группе сверстников использовалась методика вербального выбора “День рождения» (обработка результатов, предложенная Я.Л. Коломинским)[1].

В исследовании приняли участие 80 детей старшего дошкольного возраста, посещающих ГБО СОШ «Школа № 806», подразделение 7 г. Москвы (60 детей) и ООО «ВинВинКидс» г. Москвы (20 детей, обучающихся по методу Монтессори). Для статистической обработки данных использовался непараметрический критерий Манна-Уитни.

\section{Результаты исследования}

Особенности восприятия образа социального взрослого (воспитателя). $\mathrm{B}$ результате проведенного исследования были получены следующие результаты. К особенностям восприятия социального взрослого в старшем дошкольном возрасте можно отнести следующие характеристики. У детей преобладает положительное отношение к социальному взрослому. У $85 \%$ детей отмечается высокая значимость воспитателя и положительное отношение, 15\% детей демонстрируют амбивалентное отношение. Содержание образа воспитателя отличается слабой дифференцированностью, что свидетельствует о начальном этапе развития когнитивного компонента социального образа. Большинство детей определяют воспитателя с помощью 1-2 характеристик (52\% детей), реже используют в описании 3-4 характеристики (38\%). Определяющим при осознании образа социального взрослого является его имя, качества эмоциональной сфреры («добрая», «улыбчивая", «веселая»), характеристики совместной деятельности и внешняя 
привлекательность. Все дети, при описании своего воспитателя по рисунку обозначили его имя, 83\% детей обозначили качества эмоциональной сферы воспитателя, 76\% детей обозначили разные виды совместной деятельности с воспитателем, 50\% - особенности внешней привлекательности. Наименьшее значение в образе воспитателя для дошкольников имеют интеллектуальные качества (выделили 7\% детей) и качества дисциплинатора (10\% детей отметили, что воспитатель их «воспитывает», «ругается» или «следит за поведением»). Контент анализ ответов детей показал, что в качестве предпочитаемых видов деятельности с воспитателем старшие дошкольники выделяют занятия (40\% детей), игру (33\% детей) и творческие виды деятельности (выделили 26\% детей).

Особенности образа сверстника у детей старшего дошкольного возраста. К особенностям восприятия сверстника у детей старшего дошкольного возраста можно отнести преобладание положительного отношения к сверстнику, но более амбивалентного, чем к взрослому, высокую значимость и слабую дифференцированность образа сверстника. 85\% детей используют в описание друга только 1-2 характеристики, что говорит о начальном этапе развития когнитивного компонента социального образа. У $67 \%$ детей отмечается положительное отношение к сверстнику, у 33\%-амбивалентное, конкурентное отношение к сверстнику. При описании друга, 85\% детей выделяют отношение к себе («он со мной дружит», «он играет со мной»), 64\% детей выделяют качества личности и качества эмоциональной сферы («добрый», «смешит меня» и др.) Особенности внешности выделяют $36 \%$ детей, а также $29 \%$ детей осознают и выделяют умения и способности сверстника («быстро бегает», «красиво рисует» и др.).

Особенности образа проблемных ситуаций общения в пространстве общения со сверстниками. При восприятии проблемных ситуаций в общение со сверстниками дети демонстрируют высокие показатели развития социального интеллекта. 87\% детей без затруднения понимают содержание проблемных ситуаций, изображенных на картинке (ситуация отвержения, ситуация распределения, ситуация порчи игрушки или продуктов деятельности). У детей преобладают конструктивные варианты решения проблемных ситуаций (73\% детей), при этом каждый четвертый ребенок (27\%) использует неконструктивные способы решения проблемных ситуаций в пространстве общения со сверстниками («обижусь», «скажу папе, он его накажет», «буду плакать»). Характерной особенностью детей старшего дошкольного возраста является узкий поведенческий репертуар решения проблемных ситуаций общения. Большинство детей предлагают 1-2 решения проблемной ситуации, испытывают трудности в ситуации поиска разных вариантов разрешения ситуации. Можно предположить, что у детей недостаточно опыта конструктивного решения проблемных ситуаций. Данная зона развития находится в сорере стихийной социализации, при этом, на наш взгляд, обладает широким развивающим потенциалом и требует пристального внимания со стороны взрослого. 
Взаимосвязь уровня популярности в группе сверстников и особенностей социальной перцепции у старших дошкольников. Дети с разным социометрическим статусом (благоприятным и неблагоприятным) имеют как сходства, так и различия в характеристиках социальной перцепции. Дети не различаются характером эмоционального отношения и степенью значимости, структурой образа социального взрослого и сверстника. Различия наблюдаются в содержание образа сверстника. Так, дети с благоприятным статусом в большей степени определяют друга через личностные качества (75\%), тогда как дети с неблагоприятным статусом чаще определяют друга через характеристики отношения к себе (96\%). Данные результаты подтверждают выводы, полученные Е.О. Смирновой [4]. При восприятии проблемных ситуаций общения дети с разным статусом не различаются уровнем развития социального интеллекта. Различия наблюдаются в способах решения проблемных ситуаций и степенью гибкости поведения в процессе решения проблемных ситуаций. Дети с благоприятным статусом чаще решают проблемные ситуации конструктивно (85\% у БС и 69\% у детей с НС), также у них отмечаются более высокие показатели гибкости, что свидетельствует о более широком репертуаре поведения, наличие разнообразных способов решения проблемных ситуаций. Таким образом, особенности социальной перцепции детей 57 лет взаимосвязаны с успешностью в группе сверстников.

Влияние социального контекста на развитие социальной перцепции у детей 5-7 лет. Для реализации данного этапа исследования был проведен сравнительный анализ особенностей социальной перцепции у детей, посещающих разные типы ДОО. В исследование участвовали дети, посещающие традиционный детский сад и дети, посещающие детский сад Монтессори.

Сравнительный анализа полученных данных показал, что социальный контекст оказывает существенное влияние на характеристики социальной перцепции. Были обнаружены особенности, которые в меньшей степени подвержены влиянию социального контекста и особенности, которые значимо различаются в зависимости от контекста. Рассмотрим полученные результаты. Дети из разных организаций существенно не различаются эмоциональным компонентом образа социального взрослого и содержанием образа. Отличия отмечаются в степени диффференцированности, сложности образа взрослого и структуре предпочтений совместной деятельности с воспитателем. Дети из разных типов учреждения значимо не различаются характером и содержанием восприятия образа сверстника. Различия наблюдаются в степени дифференцированности и более широком поведенческом репертуаре поведения у детей из детских садов Монтессори. Таким образом, значимые различия (по критерию Манна-Уитни, при $\mathrm{p}<0,05)$ по всем аспектам изучения социального восприятия касаются степени диффреренцированности социального образа и некоторых содержательных характеристик образа социального взрослого, образа сверстника и образа 
проблемных ситуаций общения. Можно предположить, что условия разновозрастной, немногочисленной группы в детских садах Монтессори, доступность взрослого (в группе всегда находятся трое взрослых), ориентация на индивидуальные особенности и склонности ребенка способствуют благоприятному социальному развитию и развитию самосознания дошкольника.

Таким образом, старший дошкольный возраст является сенситивным периодом развития социальной перцепции. Характер социальной перцепции дошкольника определяется возрастными особенностями, а также характером социального контекста. Полученные результаты позволяют предположить, что успешность социального развития детей старшего дошкольного возраста определяется, прежде всего, развитием эмоционального компонента социального образа. Данный результат подтверждается многими исследованиями сферы социализации детей в различных психологических школах. Так, Смирнова Е.О. доказывает, что именно положительное отношение, сформированное чувство доверия, чувство общности и сопричастности определяет успешность социального развития детей [4]. Еще одной особенностью социальной перцепции дошкольника является начальный уровень развития когнитивного компонента образа взрослого и сверстника. На наш взгляд, данная особенность может рассматриваться как пространство развития социальной компетентности дошкольника через расширение опыта и представлений о социальной реальности. По результатам исследования, именно данная сорера социальной перцепции определяется характером социального контекста. Актуальными являются вопросы разработки технологий и инструментов осознанного и целенаправленного сопровождения сореры социального развития детей [5].

\section{Литература}

1. Авдулова Т.П., Хузеева Г.Р. Личностная и коммуникативная компетентности современного дошкольника. М.: МПГУ, 2013.

2. Андреева, Г.М. Психология социального познания: учебное пособие для студентов вузов. М.: Аспект Пресс, 2005.

3. Лисина М.И. Формирование личности ребенка в общении. Спб.: Питер, 2009.

4. Смирнова, Е.О. Межличностные отношения дошкольников. Диагностика, проблемы, коррекции. М.: Владос, 2005.

5. Хузеева Г.Р. Диагностика и развитие коммуникативной компетентности дошкольника. М.: Гуманитар. изд. центр ВЛАДОС, 2014. 


\section{FEATURES OF SOCIAL PERCEPTION IN CHILDREN OF PRESCHOOL AGE \\ Huzeeva G. R. (Moscow State Pedagogical University, Moscow, Russia)}

The article discusses the development of the emotional and cognitive component of the social adult's image, the peer image and the perception features of the problematic situations of communication in the interaction space with peers in children 5-7 years old. From the article it is shown that the development of the emotional component is ahead of the development of the cognitive component of the social image. At the same time, the content and structure of the image of a social adult person and the image of a peer have both similarities and differences. Features of the image of an adult, peer and features of perception and problem solving reflect the basic patterns of children's communication development. The relationship was found between the level of popularity in the peer group and the level of social perception in older children. The influence of social context on the development of social perception in children 5-7 years old is shown. The article identifies the problem of developing technologies that accompany the social development of preschoolers.

Keywords: children of preschool age, social perception, image of social adult, image of peer, problem situations of communication with peers. 